
\title{
$\begin{array}{ll}\text { Research Square } & \begin{array}{l}\text { Preprints are preliminary reports that have not undergone peer review. } \\ \text { They should not be considered conclusive, used to inform clinical practice, } \\ \text { or referenced by the media as validated information. }\end{array}\end{array}$
}

\section{Heparanase Modulation by Wingless/INT (Wnt)}

\section{Carina Mucciolo Melo}

UNIFESP: Universidade Federal de Sao Paulo

Helena Bonciani Nader

UNIFESP: Universidade Federal de Sao Paulo

Giselle Zenker Justo

UNIFESP: Universidade Federal de Sao Paulo

Maria Aparecida Silva Pinhal ( $\square$ maspinhal@yahoo.com.br)

Universidade Federal de São Paulo: Universidade Federal de Sao Paulo https://orcid.org/0000-00034001-1663

\section{Research Article}

Keywords: heparanase-1, heparan sulfate, heparin, cell signalling, heparanase regulation, glycosaminoglycans

Posted Date: March 10th, 2021

DOI: https://doi.org/10.21203/rs.3.rs-256563/v1

License: (c) (i) This work is licensed under a Creative Commons Attribution 4.0 International License. Read Full License

Version of Record: A version of this preprint was published at Molecular Biology Reports on April 23rd, 2021. See the published version at https://doi.org/10.1007/s11033-021-06348-3. 


\section{Abstract}

Heparanase is an endo-beta-glucuronidase, the only enzyme in mammals capable of cleaving heparan sulfate/heparin chains from proteoglycans. The oligosaccharides generated by heparanase present extensive biological functions since such oligosaccharides interact with adhesion molecules, growth factors, angiogenic factors and cytokines, modulating cell proliferation, migration, inflammation, and carcinogenesis. However, the regulation of heparanase activity is not fully understood. It is known that heparanase is synthesized as an inactive $65 \mathrm{kDa}$ isoform and that post-translation processing forms an active $50 \mathrm{kDa}$ enzyme. In the present study, we are interested in investigating whether heparinase is regulated by its own substrate as observed with many other enzymes. Wild-type Chinese hamster (Cricetulus griséus) ovary cells (CHO-K1) were treated with different doses of heparin. Heparanase expression was analyzed by Real-time PCR and flow cytometry. Also, heparanase activity was measured. The heparanase activity assay was performed using a coated plate with biotinylated heparan sulfate. In the present assay, a competitive heparin inhibition scenario was set aside. Exogenous heparin trigged a cell signaling pathway that increased heparanase mRNA and protein levels. The Wnt/beta-catenin pathway, judged by TCF-driven luciferase activity, seems to be involved to enhance heparanase profile during treatment with exogenous heparin. Lithium chloride treatment, an activator of the Wnt/betacatenin pathway, confirmed such mechanism of transduction in vivo using zebrafish embryos and in vitro using $\mathrm{CHO}-\mathrm{K} 1$ cells. Taken together the results suggest that heparin modulates heparanase expression by Wnt/beta-catenin.

\section{Introduction}

Heparanase-1 or heparanase (HPSE), an endo-beta-glucuronidase, is the only enzyme in mammals capable of cleaving heparan sulfate/heparin chains from proteoglycans. The oligosaccharides generated by heparanase present extensive biological functions since such oligosaccharides interact with adhesion molecules, growth factors, angiogenic factors and cytokines, modulating cell proliferation, migration, inflammation, and carcinogenesis. Furthermore, heparanase is capable of digesting heparan sulfate in the extracellular matrix $(E C M)$, thereby allowing cell invasion $(1,2)$. Increased expression of heparanase is closely related to poor prognosis in several pathological conditions, such as the process of tumor development, epithelial-mesenchymal transition, inflammation, and angiogenesis (3-10). Higher levels of heparanase expression and enzymatic activity are frequently used as a marker for diagnosis and prognosis of malignant tumors $(7,11)$.

Several strategies for inhibiting heparanase activity have been developed, including anti-heparanase antibodies, DNA aptamers displaying high affinity and specificity for the active site of the enzyme, modified heparins, and synthetic polysaccharides PI-88 (a mixture of highly sulfated, monophosphorylated mannose oligosaccharides), SST0001 (chemically modified heparin), and M402 (heparan sulfate mimetic). Some of these compounds are undergoing clinical trials with good results, PI88 (Phase-III studies in hepatocellular carcinoma), PG-545 (Phase-I in 
patients with advanced solid tumors, SST0001 (Phase-I studies with multiple myeloma) and M-402 (Phase-ll studies with pancreatic cancer) (11-13). Weissmann and co-workers using specific antibodies demonstrated an inhibitory effect of heparanase activity and a significant decrease in the tumor growth of non-Hodgkin's B lymphoma in mice model (14).

Heparanase is synthesized as an inactive $65 \mathrm{kDa}$ isoform, which is cleaved by proteolysis in late endosomes/lysosomes by cathepsin L, releasing an active enzyme, which consists of a heterodimer of $50 \mathrm{kDa}$ and $8 \mathrm{kDa}(4,15,16)$. Both $50 \mathrm{kDa}$ and $8 \mathrm{kDa}$ subunits form a heterodimer that is 100 -fold more active than the pro-enzyme $(65 \mathrm{kDa})(17)$. Thus, the post-translation processing of heparanase regulates its enzymatic activity. Therefore, slight differences in mRNA expression may not be enough to change heparanase activity due to post-translational activation mechanisms (18).

Previous results obtained by our group (19) demonstrated that in CHO-K1, heparanase is located mostly in the ECM and cell surface. However, heparanase is present inside the cell in mutant $\mathrm{CHO}-745$, which has a significantly lower amount of glycosaminoglycans, suggesting that sulfated glycosaminoglycans can modulate heparanase location. In addition, $\mathrm{CHO}-\mathrm{K} 1$ cell line was treated with 4-methylumbelliferone (7hydroxy-4-methyl coumarin or 4-MU, Sigma-Aldrich), a potent chemotherapeutic agent that completely inhibits cellular synthesis of glycosaminoglycans, due to inhibition of the enzyme glucuronosyltransferase (UGT) (20-22). Surprisingly, heparanase expression significantly decreased after treatment with 4-MU. Moreover, the heparanase levels were not related to the sulfation of glycosaminoglycans (19).

It is well known that heparin can inhibit the heparanase enzyme by competing with the substrate heparan sulfate (23). Also, it has already been demonstrated that heparanase expression can be stimulated by Early Growth Response 1 (EGR1), estrogen and p53 $(24,25)$. Breast cancer patients treated with tamoxifen, an estrogen receptor inhibitor, have decreased heparanase expression in the circulating lymphocytes (26). In addition, cathepsin $L$ activity is also regulated by glycosaminoglycans $(18,27-29)$. Despite all our knowledge about heparanase, the regulation of enzymatic activity is not fully understood. Therefore, we decided to investigate the mechanisms of heparanase modulation by exogenous heparin.

In the present study, we are interested in investigating whether heparanase levels are regulated by its own substrate as observed with many other enzymes. Also, we evaluated if Wnt/beta-catenin might be involved in such regulation. We have used techniques that allow us to suggest the involvement of the Wnt signaling in our model. The Wnt/beta-catenin pathway acts to control the transcription of genes through the binding of a complex of beta-catenin and Transcription Factor (TCF) to specific promoter elements. The activity of this final step in the Wnt/beta-catenin pathway can be measured using a luciferase reporter construct (30). Thus, CHO-K1 cells were transiently transfected with the pTOPFLASH or pFOPFLASH (containing a 'far from optimal' TCF binding site). In addition, we also investigated the response of cells to lithium chloride ( $\mathrm{LiCl}$ ), which is a known inhibitor of Glycogen Synthase Kinase 3 (GSK-3) phosphorylation, thus stimulating the canonical Wnt signaling pathway. We believe that these 
combined results allowed us to evidence that heparin can modulate the expression of heparanase, suggesting that the Wnt pathway is involved in such modulation.

\section{Materials And Methods}

Cell culture

Wild-type Chinese hamster ovary cells (CHO-K1, Cricetulus griséus) were obtained from Dr. Esko (University of California, La Jolla, USA). The CHO-K1 cell line was kept in Ham's F-12 Medium (Cultilab®, Brazil), containing 10\% Fetal Bovine Serum (FBS), (ThermoFisher Scientific, USA), $50 \mathrm{U} / \mathrm{ml}$ penicillin G (ThermoFisher Scientific) and $50 \mu \mathrm{g} / \mathrm{ml}$ streptomycin sulfate (ThermoFisher Scientific). The cells were maintained in an atmosphere of $2.5 \% \mathrm{CO} 2$ at $37^{\circ} \mathrm{C}$. All experiments were conducted in the absence of FBS.

Zebrafish

Wild-type zebrafish (Danio rerio) embryos were maintained $28^{\circ} \mathrm{C}$ in $\mathrm{E} 3$ medium $(\mathrm{NaCl} 0.29 \mathrm{~g} / \mathrm{L}, \mathrm{KCl} 0.013$ $\mathrm{g} / \mathrm{L}, \mathrm{CaCl}_{2} .2 \mathrm{H}_{2} \mathrm{O} 0.048 \mathrm{~g} / \mathrm{L}, \mathrm{MgCl}_{2} .6 \mathrm{H} 2 \mathrm{O} 0.0815 \mathrm{~g} / \mathrm{L}$, methylene blue $\left.0.0001 \%\right) .3$ days post-fertilization embryos were treated with lithium chloride.

Treatment with heparin

Heparin (porcine intestinal mucosa, Sigma-Aldrich, USA) was added to the culture medium of CHO-K1 $(100 \mu \mathrm{g} / \mathrm{mL}, 18 \mathrm{U} / \mathrm{mL}$ and $500 \mu \mathrm{g} / \mathrm{mL}, 90 \mathrm{U} / \mathrm{mL})$ and incubated for 18 hours at $37^{\circ} \mathrm{C}$. This $\mathrm{CHO}-\mathrm{K} 1$ treatment was performed to evaluate the effect of exogenous heparin on heparanase expression. These dosages were used since some studies in the literature found competition with endogenous heparan sulfate using this amount range $(31,32)$.

Real-time PCR

- Quantitative Real-Time PCR (qPCR) was used to evaluate heparanase expression. Total RNA was extracted from CHO-K1 cells and zebrafish embryos using Trizol reagent (ThermoFisher Scientific) according to manufacturer's instructions. Samples of cDNA were obtained with $1 \mu \mathrm{g}$ of pure RNA for reverse transcriptase PCR (RT-PCR), using the ImProm-IIM Reverse Transcription System (Promega, USA) according to manufacturer's instructions. qPCR was performed using SYBR Green Master Mix (2X) (ThermoFisher Scientific), $1 \mu \mathrm{g}$ of CDNA and $3.0 \mu \mathrm{M}$ of each pair of specific primers. For $\mathrm{CHO}$ cell line were used: heparanase sense 5' TGG CAA GAA GGT CTG GTT AGG AGA 3', heparanase antisense 5' GCA AAG GTG TCG GAT AGC AAG GG 3'; Glyceraldehyde-3-Phosphate Dehydrogenase (GAPDH) sense 5' GGA GAA ACC TGC CAA GTA TGA 3', GAPDH antisense 5' GTT GAA GTC GCA GGA GAC AA 3'; beta-actin sense 5' CTT CCT TCC TGG GTA TGG AAT C 3' and beta-actin antisense 5' CTG TGT TGG CAT AGA GGT CTT 3'. For Danio rerio were used: eukaryotic translation elongation factor 1 alpha (EF1-a) sense 5'TGT CTC TTC TCA TCT CCA ACG A 3', EF1-a antisense 5' ACC AAA TGC TCT 
TCC ATC TTG T 3; 60S ribosomal protein L13 (RPL13a) sense 5’ AGT AGT CAG GTG TCC GAC CAT C 3', RPL13a antisense 5' TAT TCC TTC AGC CTC TGG ACA T 3'; heparanase sense 5' GGA TTT TCT TGA CCC TGA AGT G 3', heparanase antisense 5' CAG TTT GTC CAG GCC ACA TAA AA 3'. The normalization of the expression of the target gene was determined using the geometric mean between the two endogenous genes.

Enzymatic activity of heparanase using biotinylated heparan sulfate

The cellular fraction used to perform the enzymatic assay was scraped from culture plates with sodium acetate buffer, pH 5.5, and protease inhibitor cocktail (Sigma-Aldrich). Total cell protein was estimated by Pierce $^{\mathrm{TM}}$ Coomassie Plus (Bradford) Assay Kit (Thermo Fisher Scientific), as described by the manufacturer. It is important to point out that the values that express heparanase activity were adjusted by the total protein of cellular extract, to eliminate bias due to some possible anti-proliferative or proproliferative effect. Enzymatic activity of heparanase was measured using $1 \mu \mathrm{g}$ heparan sulfate $15 \%$ biotinylated (bovine kidney, Sigma-Aldrich) immobilized on a 96-well plate previous coated with protamine sulfate (Sigma-Aldrich), following the instructions described by Bouças and coworkers (33). Subsequently, the cellular fraction (15 $\mu \mathrm{g}$ of total protein) was added to the plate containing immobilized biotinylated heparan sulfate and maintained for 4 hours at $37^{\circ} \mathrm{C}$, followed by streptavidin-europium incubation (Perkin-Elmer, Finland), for 40 minutes, at room temperature. Finally, a Delfia ${ }^{\circledR}$ enhancement solution (Perkin-Elmer) was added and fluorescence was quantified following the protocol described by Melo et al (34).

Wnt activity

Luciferase reporter assay was used to evaluate Wnt activation. The cells were transiently transfected using Fugene with the TCF firefly luciferase reporters (pTOPFLASH, TCF Optimal motif) and pFOPFLASH (containing a 'Far from Optimal' TCF binding site), as described by van de Wetering and colleagues (30). pTOPFLASH and pFOPFLASH were gifts from Prof. Maikel Peppelenbosch (Erasmus University Medical Center, Rotterdam, The Netherlands). After specific treatments, the cells were lysed and luciferase activity was measured using the Steadylite Plus reporter gene assay (Perkin-Elmer, The Netherlands), according to the manufacturer's instructions. The results were calculated by the ratio of TOP/FOP to rule out some bias due to alteration in cell death or proliferation after treatments. The result was expressed relative to the control group.

LiCl treatment

To evaluate the effect of Wnt signaling on heparanase expression in $\mathrm{CHO}-\mathrm{K} 1$ lithium chloride (molecular biology grade 99\% was purchased from Sigma-Aldrich, catalog number L9650) (activator of Wnt signaling through inhibition of GSK-3) was added to the culture medium of CHO-K1 cells ( $1 \mathrm{mM})$ and incubated for 6 hours at $37^{\circ} \mathrm{C}$, followed by flow cytometry analysis. Also, zebrafish with 3 days postfertilization were treated with $\mathrm{LiCl}(2 \mathrm{mM})$ in water containing $1 \%$ DMSO for 6 hours, $28^{\circ} \mathrm{C}$. Fifty embryos per group were used to RNA extraction. Even though it is recognized that $\mathrm{LiCl}$ can inhibit other targets, its 
major effect has long been demonstrated to be GSK-3 inhibition in diverse organisms and in vitro (3537).

Flow cytometry analysis

Cells were fixed using paraformaldehyde $(2 \%)$, washed with glycine $(0.1 \mathrm{M})$, blocked with BSA $1 \%$ and permeabilized using saponin $0.01 \%$. Phospho-beta-catenin (S33/S37, R\&D System, USA, catalog number PPS020) and heparanase ( $\mathrm{H}-80$, Santa Cruz) antibodies were incubated for 18 hours at $4^{\circ} \mathrm{C}$. Cells were labeled with secondary antibodies conjugated with AlexaFluor ${ }^{\circledR} 488$ (1:250, anti-lgG rabbit or mouse, Molecular Probes) for 1 hour. Flow cytometry analysis was performed using FACS Calibur (Becton Dickinson, USA).

\section{Results}

Effect of exogenous heparin on the expression of heparanase

Heparin upregulated heparanase mRNA expression. Figure 1A shows an increase of 250-fold on heparanase mRNA expression with $500 \mu \mathrm{g} / \mathrm{mL}$ of heparin compared to $100 \mu \mathrm{g} / \mathrm{mL}$. Moreover, heparin compared to $100 \mu \mathrm{g} / \mathrm{mL}$ treatment produced an increase of 4 times over the control.

Figure 1B shows that exogenous heparin also upregulates heparanase activity in the $\mathrm{CHO}-\mathrm{K} 1$ cell line. The enzymatic activity of heparanase was enhanced 2 times with $500 \mu \mathrm{g} / \mathrm{mL}$ of heparin over $100 \mu \mathrm{g} / \mathrm{mL}$ of heparin, while an increase of 1.5 was observed between $100 \mu \mathrm{g} / \mathrm{mL}$ of heparin and the control (Fig. 1B). It is important to point out that heparin is a competitive inhibitor of heparanase. However, after heparin treatment, the culture medium was removed, and the cells harvested to determine the enzymatic activity using biotinylated heparan sulfate. Therefore, a competitive heparin inhibition scenario was set aside in the present assay.

These results suggest that the effect of heparin on mRNA expression and heparanase protein levels is concentration dependent.

Piva and co-workers showed that the depletion of glycosaminoglycan biosynthesis using 4-MU promoted a decrease of heparanase levels, indicating that glycosaminoglycans modulate heparanase since 4-MU inhibits glycosaminoglycans synthesis (19).

Mechanisms involved in heparanase modulation by heparin

The Wnt pathway and beta-catenin play a crucial role in several cellular processes, such as survival, migration, proliferation, and differentiation. It is conceivable that heparan sulfate proteoglycans act as co-receptors for a variety of ligands that regulate cell signaling. It is well known that heparan sulfate has high-affinity binding to Wnt (38). Furthermore, exogenous heparanase has been shown to modulate cellular responses to Wnt3a (39). 
The Wnt/beta-catenin signaling controls the transcription of genes through the binding of a complex of beta-catenin and TCF to specific promoter elements. The activity of this final step in the Wnt/beta-catenin cascade can be investigated using a luciferase reporter construct. Thus, $\mathrm{CHO}-\mathrm{K} 1$ cells were transiently transfected with the pTOPFLASH or pFOPFLASH reporter (30).

Heparin increased beta-catenin/TCF signaling as shown in Fig. 2. There was a 1.5-fold increase in luciferase activity after incubation with different concentrations of heparin compared to control (Fig. 2). The stimulation of Wnt activity by heparin was similar to LiCl treatment. An increase in Wnt activity corroborates with a decreased phosphorylation of beta-catenin as shown in Fig. 3.

To confirm that the Wnt/beta-catenin pathway is involved in the activation of heparanase expression, CHO-K1 cells were treated with $\mathrm{LiCl}$, as shown in Fig. 4.

In addition, zebrafish embryos were treated with $\mathrm{LiCl}$, the heparanase expression increased comparing to control group (Fig. 5).

Even though it is recognized that $\mathrm{LiCl}$ can inhibit other targets, its major effect has long been demonstrated to be GSK-3 inhibition in diverse organisms and in vitro (36). In addition, $\mathrm{LiCl}$ can modulate GSK-3/ phosphorylation on Ser9/21 by a complex mechanism. In this respect, studies have shown that inhibition of GSK-3 by lithium leads to increased N-terminal phosphorylation of GSK-3 and GSK-beta, demonstrating autoregulation of GSK-3 N-terminal serine phosphorylation. Thus, GSK-3 autoregulation could involve inhibition of a kinase or activation of a phosphatase. In the response to lithium chloride, this autoregulation implies two levels of inhibition: rapid response, direct inhibition of GSK-3 by lithium, followed by inactivation of the protein phosphatase (PP1). As a consequence of PP1 inactivation there is an increase in inhibitory phosphorylation of GSK-3 (37). Moreover, GSK-3 function in the Wnt pathway appears to be insulated from the effects of inhibitory N-terminal kinases such as Akt. It has been suggested that this inhibitory phosphorylation of GSK-3 would primarily affect Wnt-independent GSK3regulated pathways, indicating an unexpected level of signaling pathway selectivity to lithium response.

There was a shift in the curves of heparanase fluorescence as shown in Flow Cytometer analysis, median 213 (control), 273 (treatment with heparin), 385 (treatment with LiCl), suggesting an increase in heparanase protein expression compared to $\mathrm{CHO}-\mathrm{K} 1$ cells without any treatment (Control), as shown in Fig. 4.

In addition, after treatment with $\mathrm{LiCl}$, zebrafish embryos presented an enhance of heparanase expression, confirming that the same mechanism occurs in vivo, as demonstrated in Fig. 5.

The mechanisms that modulate heparanase activity and heparanase expression are still unclear. It is important to emphasize that heparin is a known inhibitor of heparanase activity since it competes with heparan sulfate for the active site of the enzyme (23). Nevertheless, in the present study the treatment of $\mathrm{CHO}-\mathrm{K} 1$ cells with heparin induced an increase in mRNA expression and protein level. 


\section{Discussion}

Piva et al. showed that treatment with 4-MU, an inhibitor of glycosaminoglycan synthesis, decreased mRNA levels of heparanase (19).

In another study, Famá and coworkers observed that higher levels of heparan sulfate increased heparanase expression and heparanase activity in placenta tissue from patients with preeclampsia (40), supporting the hypothesis that higher levels of heparan sulfate could perhaps play a role in the positive regulation of heparanase activity.

It has been previously reported that exogenous heparanase significantly alters Wnt3a (39). However, the modulation of heparanase by Wnt/beta-catenin signaling has not been studied so far. Thus, we set out to investigate whether the Wnt/beta-catenin pathway was associated with heparanase expression.

Another study showed heparin significantly increased Wnt/beta-catenin activity, concomitantly with a reduction in beta-catenin phosphorylation, corroborating the data obtained in the present study (41). Also, Alexander and colleagues demonstrated that syndecan-1 and the soluble ectodomain of syndecan- 1 were capable of increasing Wnt signaling (42). In addition, Malinauskas et al demonstrated that the enhancement of Wnt signaling by the heparin seems to be related to the inhibition of Wnt inhibitory factor 1 (WIF-1) (43).

Moreover, in the presence of Wnt activator $(\mathrm{LiCl})$, there was an enhancement of heparanase protein levels, confirming the modulation of heparanase by these pathways.

Taken together, these results appear to show that heparan sulfate/heparin may possibly regulate heparanase transcription modulated by Wnt signaling pathways.

Although the role of Wnt/beta-catenin signaling in modulating heparanase expression needs further investigation, our study does provide insights into the mechanisms by which heparan sulfate/heparin can regulate heparanase levels.

There are several published articles that show that there is a relationship between heparanase and the modulation of Wnt. However, in such assays, recombinant heparanase has been shown to negatively modulate Wnt, possibly by degradation of the heparan sulfate chains of proteoglycan syndecan-1, which corroborates with our findings since heparin, which is a heparan sulfate-like molecule, stimulates the Wnt pathway (39).

Furthermore, it is well-known that heparan sulfate can modulate tumor development through the Wnt signaling and as mentioned previously, heparin is a heparan sulfate-like $(38,44)$.

The present results demonstrated that heparin stimulates heparanase expression by modulating Wnt activity and corroborate with the data in the literature. Since heparanase is an enzyme directly related to 
carcinogenesis, our findings add important information to the current body of knowledge on cancer biology.

Therefore, the results suggest that treatment with exogenous heparin enhanced mRNA expression and protein levels of heparanase. Furthermore, the Wnt/beta-catenin signaling pathway may be involved in the molecular mechanisms of heparanase modulation in vitro and in vivo.

\section{Declarations}

\section{Conflict of Interest}

The authors declare that the research was conducted in the absence of any commercial or financial relationships that could be construed as a potential conflict of interest.

\section{Author Contributions}

All authors contributed to the study conception and design. Material preparation, data collection and analysis were performed by Carina Mucciolo Melo. The first draft of the manuscript was written by Carina Mucciolo Melo and Maria Aparecida da Silva Pinhal. All authors commented on previous versions of the manuscript. All authors read and approved the final manuscript.

\section{Funding}

The financial support was obtained from FAPESP (São Paulo Research Foundation) grant, CNPq (National Council for Technological and Scientific Development), and CAPES (Coordination for the Improvement of Higher Education Personnel).

\section{Acknowledgments}

The authors would like to thank Dr. Jeffrey D. Esko, University of California San Diego and Dr. Mikael Peppelenbosch, Erasmus University Rotterdam, for kindly providing the $\mathrm{CHO}$ cell lines and pTOPFLASH and pFOPFLASH, respectively. In addition, the authors would like to FAPESP (São Paulo Research Foundation), CNPq (National Council for Technological and Scientific Development), and CAPES (Coordination for the Improvement of Higher Education Personnel) for financial support.

\section{Data availability}

Data will be provided with reasonable request. 


\section{Ethical Statement}

All animals were treated according to the Universidade Federal de São paulo animal welfare guidelines as described and approved by UNIFESP Committee (2214150216).

\section{Consent to publish}

The authors hereby consent to publication of this study.

\section{References}

1. Barash U, Cohen-Kaplan V, Dowek I, Sanderson RD, llan N, Vlodavsky I (2010) Proteoglycans in health and disease: new concepts for heparanase function in tumor progression and metastasis. FEBS $\mathrm{J}$ 277(19):3890-3903

2. Cassinelli G, Zaffaroni N, Lanzi C (2016) The heparanase/heparan sulfate proteoglycan axis: A potential new therapeutic target in sarcomas. Cancer Lett 382(2):245-254

3. Nasser NJ (2008) Heparanase involvement in physiology and disease. Cell Mol Life Sci 65(11):1706-1715

4. Li JP, Vlodavsky I (2009) Heparin, heparan sulfate and heparanase in inflammatory reactions. Thromb Haemost 102(5):823-828

5. Rodrigues LM, Oliveira LZ, Pinhal MA (2013) Expression of heparanase isoforms in intervertebral discs classified according to Pfirrmann grading system for disc degeneration. Spine (Phila Pa 1976) 38(13):1112-1118

6. Vlodavsky I, lozzo RV, Sanderson RD (2013) Heparanase: multiple functions in inflammation, diabetes and atherosclerosis. Matrix Biol 32(5):220-222

7. Matos LL, Suarez ER, Theodoro TR, Trufelli DC, Melo CM, Garcia LF et al (2015) The Profile of Heparanase Expression Distinguishes Differentiated Thyroid Carcinoma from Benign Neoplasms. PLoS One 10(10):e0141139

8. Melo CM, Origassa CS, Theodoro TR, Matos LL, Miranda TA, Accardo CM et al (2015) Analysis of heparanase isoforms and cathepsin $B$ in the plasma of patients with gastrointestinal carcinomas: analytical cross-sectional study. Sao Paulo Med J 133(1):28-35

9. Morris A, Wang B, Waern I, Venkatasamy R, Page C, Schmidt EP et al (2015) The role of heparanase in pulmonary cell recruitment in response to an allergic but not non-allergic stimulus. PLoS One 10(6):e0127032

10. Waisberg J, Theodoro TR, Matos LL, Orlandi FB, Serrano RL, Saba GT et al (2016) Immunohistochemical expression of heparanase isoforms and syndecan-1 proteins in colorectal adenomas. Eur J Histochem 60(1):2590 
11. Zhang J, Yang JM, Wang HJ, Ru GQ, Fan DM (2013) Synthesized multiple antigenic polypeptide vaccine based on B-cell epitopes of human heparanase could elicit a potent antimetastatic effect on human hepatocellular carcinoma in vivo. PLoS One 8(1):e52940

12. McKenzie EA (2007) Heparanase: a target for drug discovery in cancer and inflammation. $\mathrm{Br} \mathrm{J}$ Pharmacol 151(1):1-14

13. Rivara S, Milazzo FM, Giannini G (2016) Heparanase: a rainbow pharmacological target associated to multiple pathologies including rare diseases. Future Med Chem 8(6):647-680

14. Weissmann M, Arvatz G, Horowitz N, Feld S, Naroditsky I, Zhang Y et al (2016) Heparanaseneutralizing antibodies attenuate lymphoma tumor growth and metastasis. Proc Natl Acad Sci U S A 113(3):704-709

15. Vlodavsky I, Friedmann Y, Elkin M, Aingorn H, Atzmon R, Ishai-Michaeli R et al (1999) Mammalian heparanase: gene cloning, expression and function in tumor progression and metastasis. Nat Med 5(7):793-802

16. Zetser A, Levy-Adam F, Kaplan V, Gingis-Velitski S, Bashenko Y, Schubert S et al (2004) Processing and activation of latent heparanase occurs in lysosomes. J Cell Sci 117(Pt 11):2249-2258

17. Abboud-Jarrous G, Atzmon R, Peretz T, Palermo C, Gadea BB, Joyce JA et al (2008) Cathepsin L is responsible for processing and activation of proheparanase through multiple cleavages of a linker segment. J Biol Chem 283(26):18167-18176

18. Novinec M, Lenarcic B, Turk B (2014) Cysteine cathepsin activity regulation by glycosaminoglycans. Biomed Res Int 2014:309718

19. Piva MB, Suarez ER, Melo CM, Cavalheiro RP, Nader HB, Pinhal MA (2015) Glycosaminoglycans affect heparanase location in $\mathrm{CHO}$ cell lines. Glycobiology 25(9):976-983

20. Kudo D, Kon A, Yoshihara S, Kakizaki I, Sasaki M, Endo M et al (2004) Effect of a hyaluronan synthase suppressor, 4-methylumbelliferone, on B16F-10 melanoma cell adhesion and locomotion. Biochem Biophys Res Commun 321(4):783-787

21. Yoshihara S, Kon A, Kudo D, Nakazawa H, Kakizaki I, Sasaki M et al (2005) A hyaluronan synthase suppressor, 4-methylumbelliferone, inhibits liver metastasis of melanoma cells. FEBS Lett 579(12):2722-2726

22. Nakazawa H, Yoshihara S, Kudo D, Morohashi H, Kakizaki I, Kon A et al (2006) 4methylumbelliferone, a hyaluronan synthase suppressor, enhances the anticancer activity of gemcitabine in human pancreatic cancer cells. Cancer Chemother Pharmacol 57(2):165-170

23. Bar-Ner M, Eldor A, Wasserman L, Matzner Y, Cohen IR, Fuks Z et al (1987) Inhibition of heparanasemediated degradation of extracellular matrix heparan sulfate by non-anticoagulant heparin species. Blood 70(2):551-557

24. Elkin M, Cohen I, Zcharia E, Orgel A, Guatta-Rangini Z, Peretz T et al (2003) Regulation of heparanase gene expression by estrogen in breast cancer. Cancer Res 63(24):8821-8826

25. Baraz L, Haupt Y, Elkin M, Peretz T, Vlodavsky I (2006) Tumor suppressor p53 regulates heparanase gene expression. Oncogene 25(28):3939-3947 
26. Theodoro TR, de Matos LL, Sant Anna AV, Fonseca FL, Semedo P, Martins LC et al (2007) Heparanase expression in circulating lymphocytes of breast cancer patients depends on the presence of the primary tumor and/or systemic metastasis. Neoplasia 9(6):504-510

27. Mason RW, Massey SD (1992) Surface activation of pro-cathepsin L. Biochem Biophys Res Commun 189(3):1659-1666

28. Ishidoh K, Kominami E (1995) Procathepsin L degrades extracellular matrix proteins in the presence of glycosaminoglycans in vitro. Biochem Biophys Res Commun 217(2):624-631

29. Li Z, Yasuda Y, Li W, Bogyo M, Katz N, Gordon RE et al (2004) Regulation of collagenase activities of human cathepsins by glycosaminoglycans. J Biol Chem 279(7):5470-5479

30. van de Wetering M, Cavallo R, Dooijes D, van Beest M, van Es J, Loureiro J et al (1997) Armadillo coactivates transcription driven by the product of the Drosophila segment polarity gene dTCF. Cell 88(6):789-799

31. Wuppermann FN, Hegemann JH, Jantos CA (2001) Heparan sulfate-like glycosaminoglycan is a cellular receptor for Chlamydia pneumoniae. J Infect Dis 184(2):181-187

32. Schowalter RM, Pastrana DV, Buck CB (2011) Glycosaminoglycans and sialylated glycans sequentially facilitate Merkel cell polyomavirus infectious entry. PLoS Pathog 7(7):e1002161

33. Boucas RI, Trindade ES, Tersariol IL, Dietrich CP, Nader HB (2008) Development of an enzyme-linked immunosorbent assay (ELISA)-like fluorescence assay to investigate the interactions of glycosaminoglycans to cells. Anal Chim Acta 618(2):218-226

34. Melo CM, Tersariol IL, Nader HB, Pinhal MA, Lima MA (2015) Development of new methods for determining the heparanase enzymatic activity. Carbohydr Res 412:66-70

35. Klein PS, Melton DA (1996) A molecular mechanism for the effect of lithium on development. Proc Natl Acad Sci U S A 93(16):8455-8459

36. Hedgepeth CM, Conrad LJ, Zhang J, Huang HC, Lee VM, Klein PS (1997) Activation of the Wnt signaling pathway: a molecular mechanism for lithium action. Dev Biol 185(1):82-91

37. Zhang F, Phiel CJ, Spece L, Gurvich N, Klein PS (2003) Inhibitory phosphorylation of glycogen synthase kinase-3 (GSK-3) in response to lithium. Evidence for autoregulation of GSK-3. J Biol Chem 278(35):33067-33077

38. O'Connell MP, Fiori JL, Kershner EK, Frank BP, Indig FE, Taub DD et al (2009) Heparan sulfate proteoglycan modulation of Wnt5A signal transduction in metastatic melanoma cells. J Biol Chem 284(42):28704-28712

39. Ridgway LD, Wetzel MD, Marchetti D (2011) Heparanase Modulates Shh and Wnt3a Signaling in Human Medulloblastoma Cells. Exp Ther Med 2(2):229-238

40. Fama EA, Souza RS, Melo CM, Melo Pompei L, Pinhal MA (2014) Evaluation of glycosaminoglycans and heparanase in placentas of women with preeclampsia. Clin Chim Acta 437:155-160

41. Colombres M, Henriquez JP, Reig GF, Scheu J, Calderon R, Alvarez A et al (2008) Heparin activates Wnt signaling for neuronal morphogenesis. J Cell Physiol 216(3):805-815 
42. Alexander CM, Reichsman F, Hinkes MT, Lincecum J, Becker KA, Cumberledge S et al (2000) Syndecan-1 is required for Wnt-1-induced mammary tumorigenesis in mice. Nat Genet 25(3):329332

43. Malinauskas T, Aricescu AR, Lu W, Siebold C, Jones EY (2011) Modular mechanism of Wnt signaling inhibition by Wnt inhibitory factor 1. Nat Struct Mol Biol 18(8):886-893

44. Knelson EH, Nee JC, Blobe GC (2014) Heparan sulfate signaling in cancer. Trends Biochem Sci 39(6):277-288

45. Ruan J, Trotter TN, Nan L, Luo R, Javed A, Sanderson RD et al (2013) Heparanase inhibits osteoblastogenesis and shifts bone marrow progenitor cell fate in myeloma bone disease. Bone 57(1):10-17

\section{Figures}
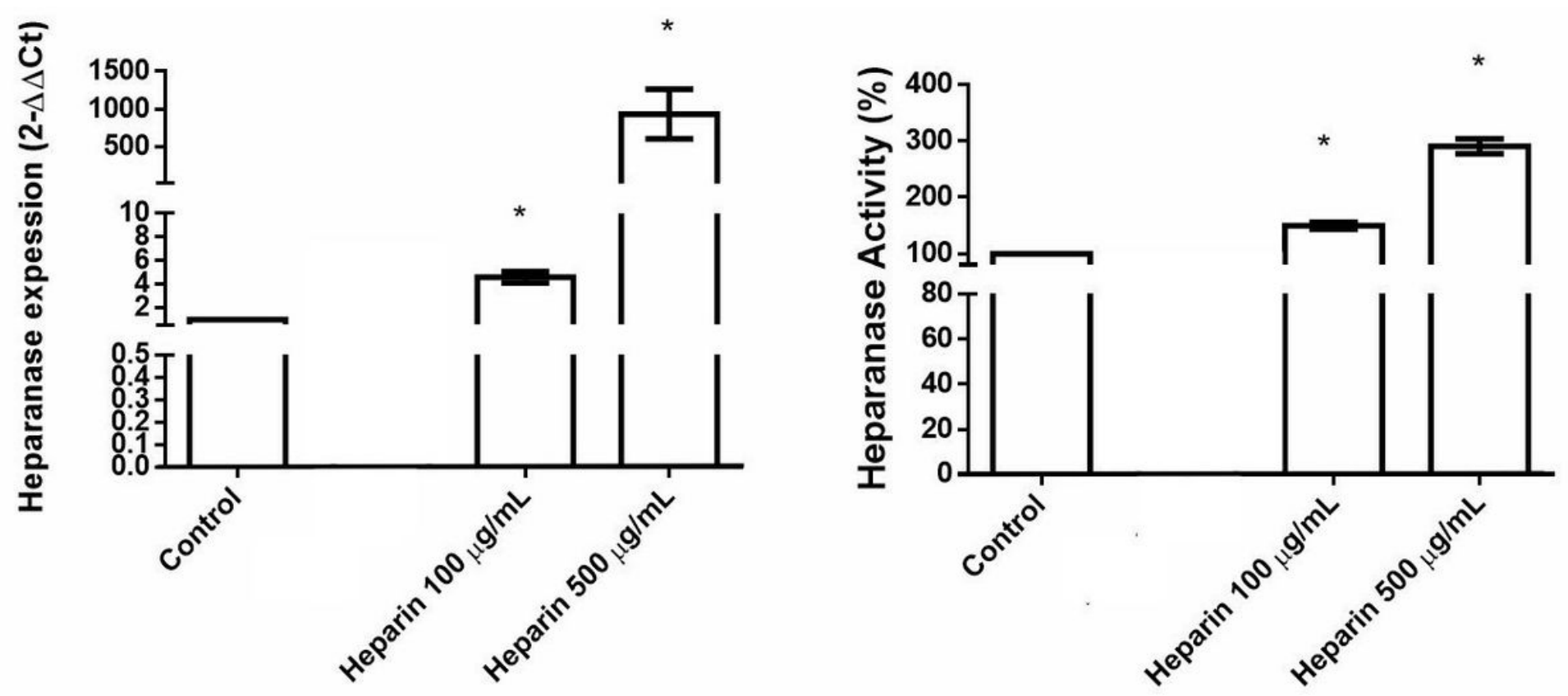

\section{Figure 1}

Expression of heparanase. (A) Heparanase mRNA expression in $\mathrm{CHO}-\mathrm{K} 1$ was investigated by quantitative Real Time-PCR. The result was expressed by $2-\Delta \Delta C$ t compared to the control. (B) After treatment, the culture medium was removed, and the cellular extract was harvested. The samples obtained from cellular fraction were used to heparanase activity assay with biotinylated heparan sulfate as described in Methods. The result was expressed by the percentage of heparanase activity comparing with the control. Control, CHO-K1 treated with 1\% DMSO; Heparin $100 \mu \mathrm{g} / \mathrm{mL}$, CHO-K1 was treated with $100 \mu \mathrm{g} / \mathrm{mL}$ of heparin; Heparin $500 \mu \mathrm{g} / \mathrm{mL}$, CHO-K1 was treated with $500 \mu \mathrm{g} / \mathrm{mL}$ of heparin. Bars means the average and lines represent standard deviations, ${ }^{*} p<0.05$, Kruskal-Wallis test. Heparin stimulated mRNA expression and the protein levels of heparanase. 


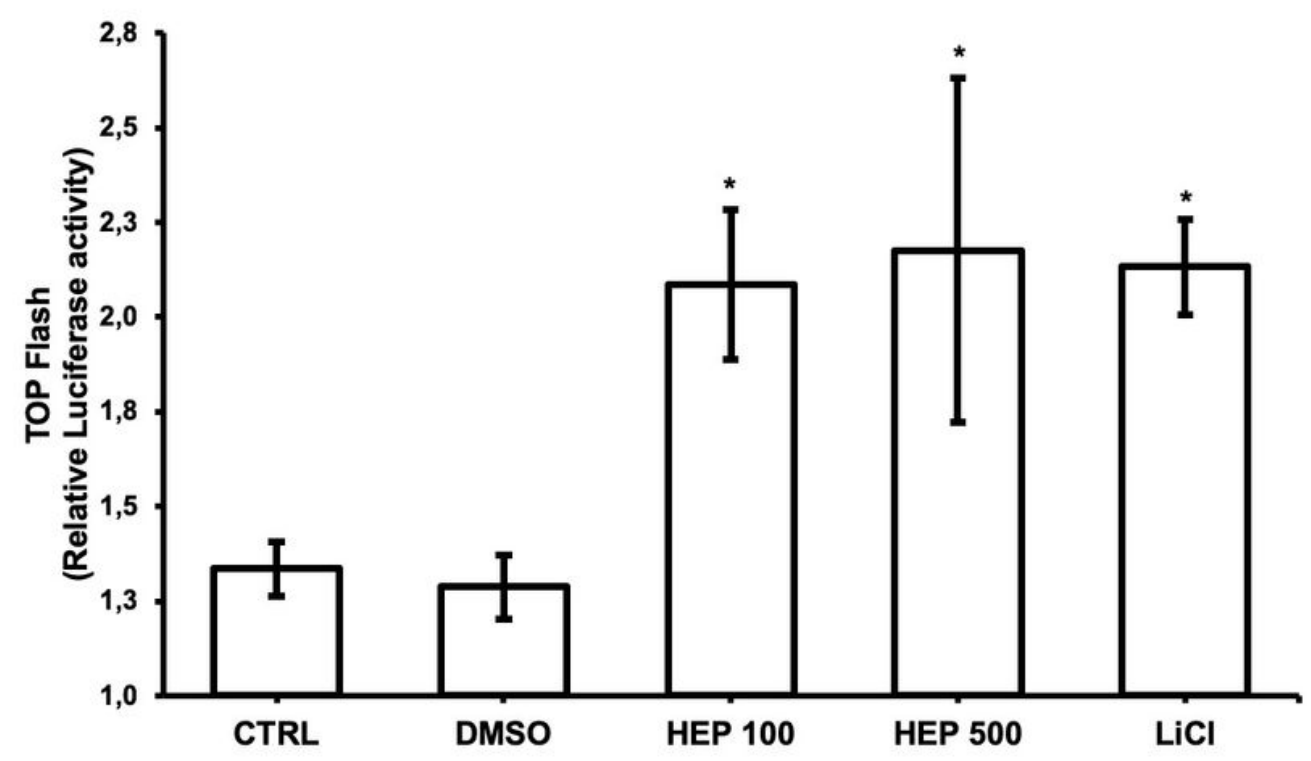

Figure 2

Wnt activity reporter assay. Wnt/beta-catenin pathway acts to control the transcription of genes through the binding of a complex of beta-catenin and TCF to specific promoter elements. The activity of this final step in the Wnt/beta-catenin pathway can be measured using a luciferase reporter construct. Thus, CHO$\mathrm{K} 1$ cells were transiently transfected with the pTOPFLASH (TCF Optimal Motif) or pFOPFLASH (containing a 'far from optimal' TCF binding site). Control, CHO-K1 without treatment; DMSO, CHO-K1 treated with 1\% DMSO; Hep 100, CHO-K1 was treated with $100 \mu \mathrm{g} / \mathrm{mL}$ of heparin; Hep 500; CHO-K1 was treated with $500 \mu \mathrm{g} / \mathrm{mL}$ of heparin; $\mathrm{LiCl}, \mathrm{CHO}-\mathrm{K} 1$ was treated with lithium chloride $(1 \mathrm{mM})$. The result was expressed as relative quantification of TOP/FOP ratio compared with the control group. TOP/FOP Flash ratio remove some bias due to proliferation or cell death. The assay was performed in triplicate. Bars means the average and lines represent standard deviations, ${ }^{\star} p<0.05$, Kruskal-Wallis test. Heparin increased Wnt signaling at a similar level of $\mathrm{LiCl}$, a well-known activator of Wnt signaling. 


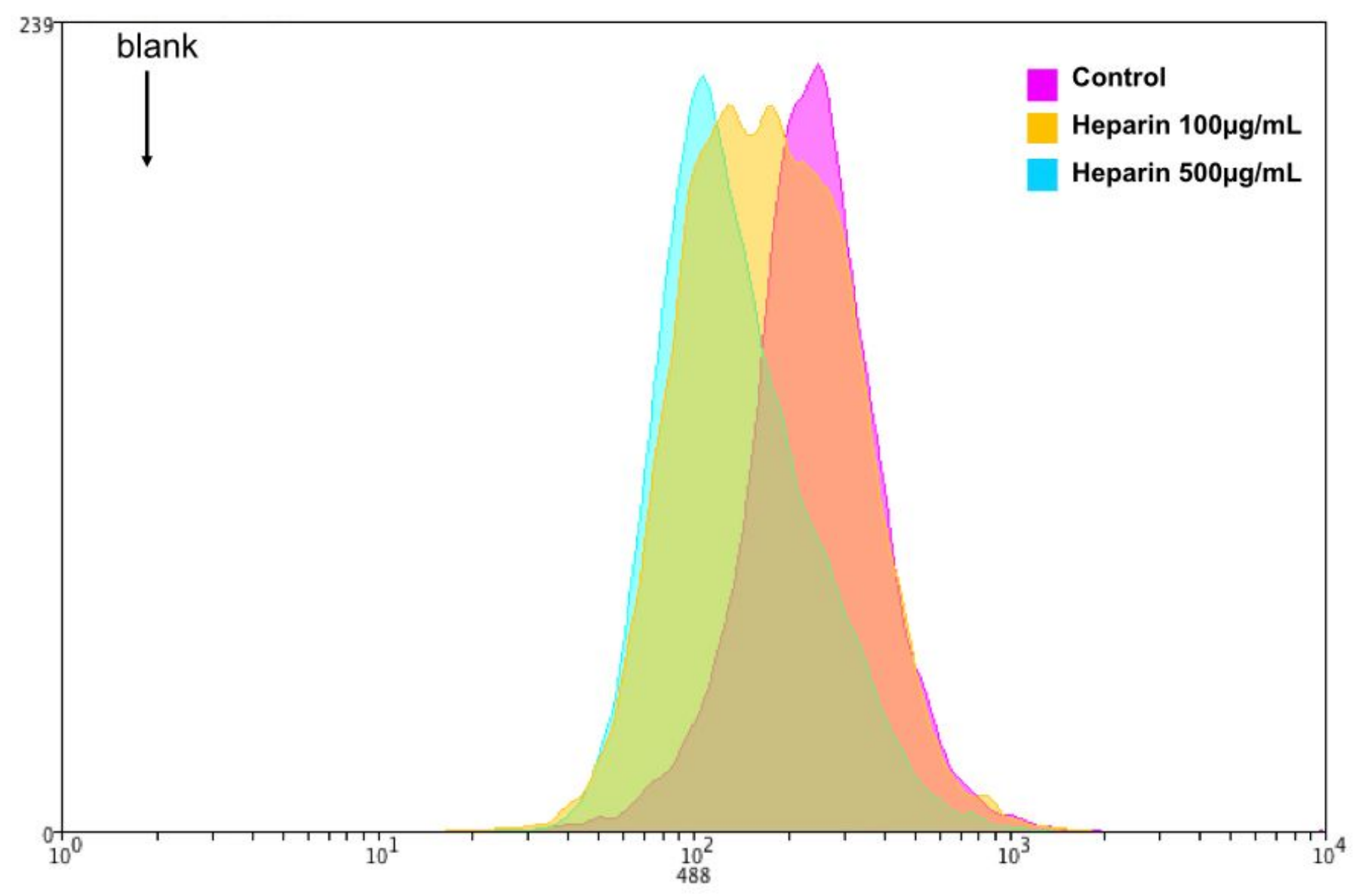

Figure 3

Phospho beta-catenin analysis. (A) Flow cytometry analysis was performed using phospho-beta-catenin antibody. Control (yellow), CHO-K1 without treatment; Heparin $100 \mu \mathrm{g} / \mathrm{mL}$ (blue), $\mathrm{CHO}-\mathrm{K} 1$ was treated with $100 \mu \mathrm{g} / \mathrm{mL}$ of heparin; Heparin $500 \mu \mathrm{g} / \mathrm{mL}$ (red), CHO-K1 was treated with $500 \mu \mathrm{g} / \mathrm{mL}$ of heparin. Blank (arrow); $\mathrm{CHO}-\mathrm{K} 1$ cells without primary antibody. (B) the numbers represent median values obtained by flow cytometry analysis (FlowJo Software). Phospho-beta-catenin increased after treatment, therefore the Wnt pathway was stimulated by heparin. 


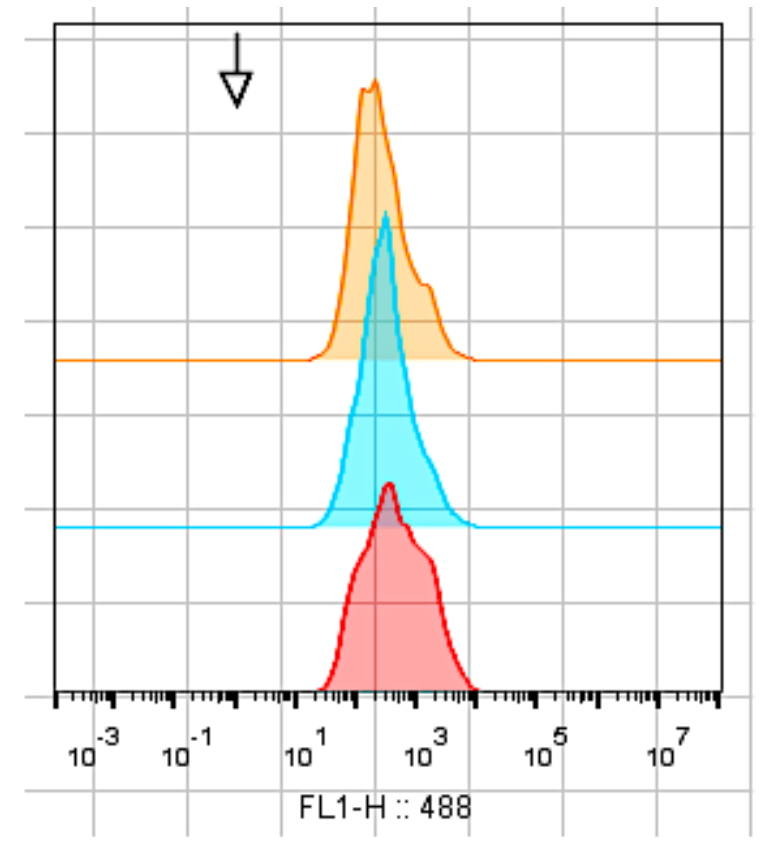

\begin{tabular}{|lr|}
\multicolumn{2}{|c|}{ Median } \\
\hline Control & $\mathbf{2 1 3}$ \\
\hline Heparin & $\mathbf{2 7 3}$ \\
\hline LiCl & $\mathbf{3 8 5}$ \\
\hline
\end{tabular}

\section{Figure 4}

Heparanase protein levels by flow cytometry analysis. (A) Flow cytometry analysis tested heparanase protein expressions. Control, CHO-K1 without treatment; Heparin, $\mathrm{CHO}-\mathrm{K} 1$ was treated with heparin (500 $\mu \mathrm{g} / \mathrm{mL}$ ). LiCl, CHO-K1 was treated with $1 \mathrm{mM}$ of lithium chloride, an activator of Wnt signaling. Blank (arrow), CHO-K1 cells without primary antibody. (B) the numbers represent median values obtained by flow cytometry analysis (FlowJo Software). Heparin and LiCl, upregulated heparanase expression.

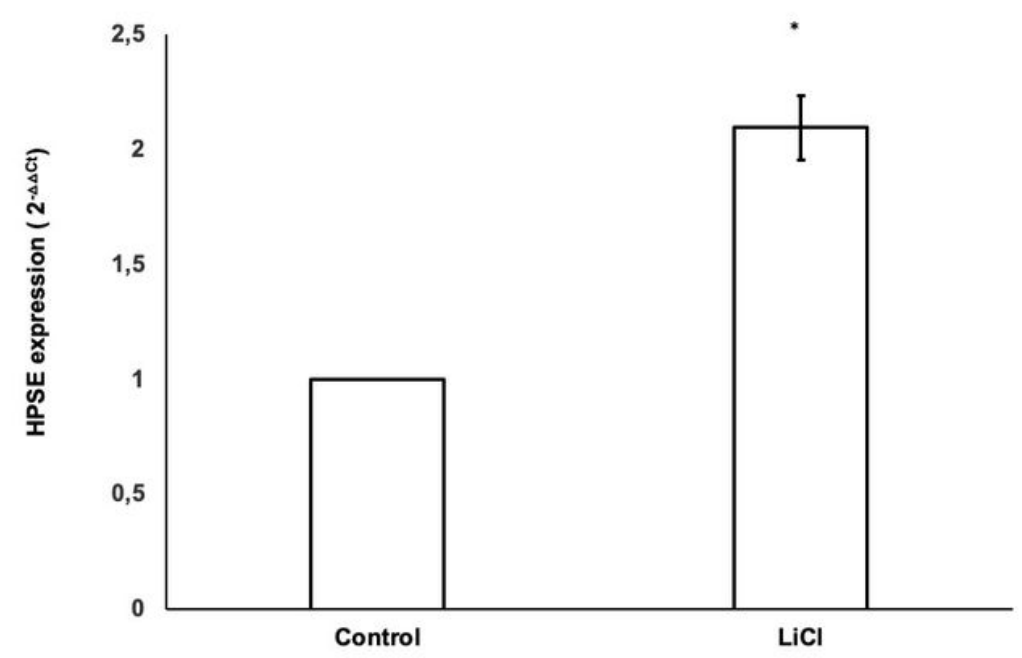




\section{Figure 5}

Heparanase expression in vivo. Heparanase mRNA expression in zebrafish embryos was investigated by quantitative Real Time-PCR. Fifty zebrafish embryos with 3 days pos-fertilization were used to RNA extraction. The result was expressed by $2-\Delta \Delta$ Ct compared to the control. Control, zebrafish embryos treated with 1\% DMSO; LiCl, zebrafish embryos treated with 1\% DMSO and $\mathrm{LiCl}(2 \mathrm{mM})$ for 6 hours. ${ }^{*} p<0.05$, ANOVA test. LiCl stimulated mRNA expression of heparanase in zebrafish embryos. 